\title{
The Relationship between domestic violence towards adolescents and their involvement in electronic bullying
}

\section{Eman M.E. Ahmed (PhD.)}

\author{
Casework Department
}

Higher Institute of Social Work-Alexandria 



\section{The Relationship between domestic violence towards adolescents and their involvement in electronic bullying}

\section{Abstract:}

This study aims to reveal the relationship between domestic violence affecting adolescents and their involvement electronic bullying, as well as the significance of differences among them, according to two variables; their gender and their parents' level of education. The study sample consisted of 213 male and female secondary school students aged 15-18 years. A scale of domestic violence and electronic bullying was designed. The study's results indicated a statistically significant correlation between levels of domestic violence affecting adolescents; verbal, emotional and physical violence, and the average degrees of their involvement in electronic bullying. The results showed that male adolescents who were more affected by domestic violence were more likely to be involved in electronic bullying than female adolescents. The results also showed that there was an inverse relationship between parents' level of education and the level of domestic violence whilst there was a direct relationship between parents' level of education and adolescents' involvement in electronic bullying.

Key words: domestic violence, electronic bullying

\section{Introduction:}

The family is the initial entity to affect an individual's personality and the formation of their identity, as individuals develop the majority of their cultural values, and form their unique characters, within the family unit (Desouky, 2002, p.129). Individuals need their families to fulfil their psychological, cultural, social and economic needs through human contact. Yet families may still become the source of many of the problems children face; violent treatment such as name-calling, beatings and neglect render the family ineffectual as a source of love, peace and emotional support. In such cases, the family becomes more dangerous to children and adolescents than other places (Al- Faraia, 2006, p.13).

Violence against children takes place in every country and society. A statistical analysis of violence against children, performed by UNICEF in 2014, revealed that more than one billion children aged 2-14, throughout the world, face physical punishment and that one of every four girls aged 14-19 face physical violence. Such violence carries many consequences making it difficult to treat and affecting children's physical, psychological and social growth (UNICEF, 2015, 
p.2). Many social workers who work in child care agencies, have indicated that the impact of repeated domestic violence and related traumas in early childhood can affect children's health and result in them going on to become either victims or perpetrators of further violence (Wilson \& Webb, 2018, p.6).

Many previous studies have indicated the many of the risks of domestic violence and their impact on children and adolescents. Adolescents facing domestic violence encounter many psychological disorders, such as anxiety, sleeping disorders, depression, nutritional disorders, speech disorders, and are prone to disability and difficulty in communicating and building relationships with others (Ahmed, 2008, p.60). These adolescents also struggle to flourish emotionally and fail to respond to their own children's emotional needs in the future (Magzoub, 2003). Other studies suggest that these adolescents lack feelings of security (Hamza, 2001), (Al-Sweety, 2012) and are prone to many behavioral problems (Sternberg, Baradaran, Abbot, Lamb, Guterman, 2006). Mekky \& Ajam's study (2008) mentioned the emotional, neurological, behavioral and mental consequences related to domestic violence. Abuleinin (2012) indicated that the families in which domestic violence occurs often raise affected children; a person who suffers violence usually attempts to follow the same path, consequently leading to a criminal path. Katibi (2012) also mentioned a relationship between domestic violence against children, including psychological loneliness, and low levels of education of both parents.

A study performed by Bardi and Tarli (2001) found that the percentage of parents who commit mild violence against their children, such as pushing or slapping, is $77 \%$, whilst strong violence such biting or burning is $8 \%$. Al-Ratrout (2001) performed a study indicating that the most common form of abuse is physical abuse, followed by negligence then sexual abuse. It also showed that the female children of parents of low income are the group most likely to be subjected to violence. The study of Al-Masry (2004), found that language used by parents against children related to scolding, child rejection and insults, and that male children are more subject to these abuses than female children. Ghazwan's study (2015) agreed with AlMasry's in finding that verbal violence is the most prevalent type of domestic violence, followed by physical violence and physical negligence, and that there is a significant relationship between both parents' academic achievement, the family's economic status and the 
degree of their children's exposure to domestic violence. Abu Zeid's study (2010) referred to the role of the media in eliminating domestic violence. Also, Al-Qous (2014) mentioned the role of social upbringing and familial disorganization in violence against children. The study also emphasized the necessity of educating students and parents about the risks of domestic violence.

The above shows that domestic violence poses devastating risks for children, threatening their very existence and development. The Committee on the Rights of the Child identifies the risks as follows; fetal and non-fetal injuries that might lead to disabilities, health problems, cognitive disorders, emotional and psychological problems, developmental and behavioral problems; such as evading school, antisocial behavior, damaging relations with others, substance abuse and law violation (UNICEF, 2015, p.5).

So, the studies agree that there are several strands to the impact of domestic violence on adolescents and their future behavior, thus referring to the importance of social work's role in the family field performed through specialized institutions. The social worker shall work with parents to encourage them to employ methods for treating their children appropriately, and will work directly with children to enhance mother-child relationships, so social workers can build strong connections with different institutions and encourage the delivery of their services to all families (Webb, 2013, p.3) \& (Bennett, 2015, p.1).

Suffering from social and psychological problems that might lead to anxiety, depression, loneliness, aggression and social-rejection usually drives an individual to avoid real life interaction with others, instead turning to simulated reality in order to compensate for their suffering. Lenhart, Madden, Macgill, Smith (2007) emphasized that adolescents increasingly use the internet on a daily basis for social communication with their peers and that such communication is not always performed positively. Modern means of e-communications, such as the internet, increase the intensity of e-threats, e.g. increased electronic bullying among students (Juvonen \& Gross, 2008).

Interest in performing more research has produced more studies on electronic bullying. The results of these studies indicate the increase in the rate of electronic bullying in different countries. The study of Ybarra \& Mitchell (2004), performed in the USA, showed that 1 in every 5 internet users is involved in bullying. $4 \%$ of the students stated being affected by electronic bullying, and $20 \%$ of them stated taking aggressive 
actions against others through the internet (as bullies). This study agreed with the results of the following studies; Ybarra, Espelage, Mitchell (2007), and Hinduja \& Patchin (2008). Also, Arslan, Savaser, Hallett, Balci (2012) showed that students bullied their peers on the internet through text messages, chat messages and emails. This also agreed with the results of Floros, Siomos, Fisoun, Dafouli, Geroukalis (2013). Zhou et al. (2013) showed in a study performed in China, that electronic bullying is widespread among high school students as victims or bullies. Al-Ammar (2016), Almakanin, Younis, Alhiary (2018), mentioned that males are more addicted to the internet and use it for bullying far more frequently, in addition to the finding that electronic bullying rates were high among students with behavior disorders.

The National Crime Prevention Council has identified the tactics often used by adolescent e- bullies. These include pretending to be someone else on the internet in order to deceive others, spreading lies and rumors about their victims, luring others to reveal their personal information, posting and reposting insulting text messages and unauthorized posting of victims' photos (Bullying - National Crime Prevention, Council, 2018).

Studies have begun to identify the social and psychological impacts of electronic bullying on victims. The Social and Psychological Research Journal posted reports about the critical impacts of electronic bullying; noting low self-respect, loneliness, distress, distrust of others and more extreme impacts such as selfharm. Many children have even killed others and committed suicide after being involved in electronic bullying (Šléglová \& Cerna, 2011).

The study of (Tudkueaa, Laeheemb, Sittichaic, 2019), in Thailand, indicated that cases of electronic bullying among the study sample significantly increased their tendency towards depression compounded by group violence, media violence and oppressive parenting. Such depression indirectly leads to poor mental and physical health, difficulties in communicating with others and even suicide attempts. Markwick, Bickerdike, Wilson-Evered, Zeleznikow (2019) mentioned that perpetrators often used technology to create a sense of existence and to scare their victims by demonstrating control over their lives.

According to the above and due to the gravity of domestic violence and its negative impacts on adolescents, which includes feelings of distress and aggression, electronic bullying also has devastating impacts on the community. As well as the negative impact 
of electronic bullying, the researcher decided to focus on identifying the relationship between domestic violence suffered by adolescents and their involvement in electronic bullying.

\section{The importance of the study is shown by the following:}

1. The multiple risks posed by domestic violence affecting adolescents and its impacts that might endure throughout adulthood and characterize future behavior.

2. Previous studies have shown that electronic bullying rates are high in different countries, especially affecting adolescents, indicating its negative impact and relationship with depression and aggression.

3. The lack of studies of electronic bullying performed within the researcher's field of knowledge.

4. The necessity to research the reasons behind the problem of electronic bullying and making recommendations about ways to eliminate its impacts.

Study objectives: this study aims to:

1. Shed light on the types of domestic violence affecting adolescents and those causing the most impact.

2. Identify the problem of electronic bullying and its prevalence amongst adolescents.

3. Discern the relationship between domestic violence affecting adolescents and their involvement in electronic bullying, and identify the significance of differences between electronic bullying and domestic violence according to adolescents' gender and the level of education of their parents.

\section{Study hypotheses:}

First hypothesis: there is a positive statistically significant correlation between averages of domestic violence affecting adolescents; verbal, physical and psychological forms of violence, and the averages of electronic bullying of adolescents.

Second hypothesis: there is no statistically significant correlation between averages of domestic violence affecting adolescents and electronic bullying according to two variables; gender and parents' level of education.

\section{Study concepts:}

1. Definition of domestic violence: Violence against children is defined by Al-Marawaty (2010) as: repeated physical or psychological violence, by one or both parents, whether by deliberate beating or aggressive physical uncontrolled 
punishment, constant derision and insult of the child, lack of care and failure to provide the child's basic needs, or through exploitation of the child by caregivers and assigning them beyond their abilities. Bou-tabbal and Maaousha (2013) defined violence against children as the behaviors threatening a child's social, physical and psychological balance, through verbal, emotional and physical violence by one or both parents or the child's care givers. Phillips \& Vandenbroek (2014) define domestic violence as "violence, abuse and intimidation between people who are currently or who have previously been in an intimate relationship". The perpetrator uses violence to control and dominate the other person causing fear, physical harm and/or psychological harm. Domestic violence is a violation of human rights. The World Health Organization (2015) defines domestic violence as: "the deliberate use of force or physical force, threat or actual, against one or more persons, thus leading to a high possibility of death, mal-growth or deprivation". Domestic violence practiced against children is defined as various patterns of parental behavior directed against children as well as family conditions that cause children physical, mental and psychological damage and socially impede their development. In Abdel Gawad's (2020) study domestic violence is defined as violence that is directed from the family towards the adolescents verbally, physically or psychologically, which can negatively impact their behaviors and render them prone to depression and aggression against others.

2. Definition of electronic bullying: Willard (2007) defined electronic bullying as sending or posting negative texts or photos through the internet or any electronic communication devices. This agrees with Juvonen \& Gross (2008) who define electronic bullying as; using the internet or any other electronic communication device to insult or threaten someone else. Hinduja and Patchin (2008) defined electronic bullying as repeated and deliberate harm of others through the use of electronic devices. It is defined by Tokunaga (2010) as any behavior performed through the internet, by one or more persons whose identity remains unknown to the victim, such as repeated communication or harassment through messages aiming to harm others. Kowalski, Limber, Agatston (2012) and White (2019) suggested that electronic bullying is called harassment when 
perpetrated through the internet, e-mails and IM service in chat rooms, on web sites and internet gaming sites, and through digital messages and photos sent between smart phones. Megan (2014) referred to an electronic bully as either a person known to the target or a stranger on the internet. This study defines electronic bullying as adolescents' use of electronic communication devices to insult, threaten or harm their peers through multiple communication sites.

\section{Theories guiding the study:}

The social theory: the theorists of social theory view aggressive behavior as related to the type and nature of general culture of the community and its difficulties, that is, connected to the sub-culture of a family's circumstances, relationships, structure, methods and social upbringing techniques. This approach considers the best understanding of aggression is through the thorough examination of external environment factors surrounding individuals and affecting their behavior, in addition to the necessity of examining daily interactions taking place in an individual's or group's lives as a factor that facilitates violence and predicts it (Fayed, 2001, p.35).

Suppressive theory: Dullard has set a group of psychological laws explaining aggression and violence including; 1 . Every aggression is a result of a suppression, 2. Aggression increases as suppression increases, 3 . Aggression increases with the increase of elements of suppression, 4. The process of blocking aggression leads to later aggression, while eliminating it can lead to reducing its intensity even temporarily and 5. Aggression is directed towards the source of suppression. Aggression is described here as direct and when such aggression cannot be directed towards the original source of suppression, it can be directed towards another source with direct or symbolic relation to the original source, then such aggression can be called humor and such a phenomenon is known as "the scape goat"; like the case of a teacher who is suppressed by his/ her principal then directs aggression towards the students, for they cannot assault the principal; or a wife who is assaulted by her husband then uses violence against their children (Ghazwan, 2015, p.2161). As per the previous theories, an adolescent living within a violent family environment is considered to have a direct reason beyond their behavioral disorder and their feeling of depression, which may, in turn, lead to aggressive behavior and violence against others, which sometimes takes the form of electronic bullying. 


\section{Methodology:}

This study is an analytical qualitative study, as the researcher seeks to describe and analyze the relationship between the independent variable; the risks of domestic violence affecting adolescents, and the dependent variable; electronic bullying.

A simple random sample was selected by choosing those achieving the highest grades on the domestic violence scale. The study sample consisted of 213 high school students, 137 students of Tareqibn Ziad High School for boys in Smouha, Alexandria (121 first graders and 16 second graders), and 76 students from AL-Fawatem High School for Girls, Attarine, Alexandria (62 first graders and 14 second graders). So, the male percentage of the study sample was $64.3 \%$ and the female percentage was $35.7 \%$, with $85.9 \%$ of the sample in first grade and $14.1 \%$ in second grade, with ages ranging from 15 to 18 years. As for the parents' educational level, it was found that the majority of the sample $(40.4 \%)$ had a primary educational level, followed by $36.2 \%$ attaining a less than average school educational level, with $12.2 \%$ reaching an intermediate educational level and finally $11.1 \%$ achieving a college education. The average number of hours adolescents spent on social media sites was more than 4 hours daily, with a percentage of $93 \%$ of the sample.

\section{This study employed the following tools:}

First tool: Domestic violence scale (prepared by the researcher) - the researcher prepared the basic aspects of the scale according to the research concepts as follows; first aspect "psychological violence" represented by items (1-15), second aspect "verbal violence" represented by items (16-28) and the third aspect "physical violence" represented by items (28- 39). The scale has three degrees; "yes" equals 3 points, the highest, "sometimes" equals 2 points, medium degree, and "no" equals zero points, the lowest degree. The scale consisted of 39 items distributed between the three aspects. The highest score of the first aspect is $15 \times 3=45$, the highest score for the second and third aspects is 36 , the medium score is 24 and the lowest score for each aspect was 12 .

Scale validity: First: Content Validity: The researcher presented the scale to ten different professors in social work to assess the elements in terms of structure and relativity of the subject of the study. Accordingly, the researcher rebuilt and modified some phrases. Second: Table No. 1 showed that the relationship between the scale's aspects and the total scale's score was of acceptable correlation and 
was statically significant. Third: the validity of the scale as a whole using the terminal comparison (Discriminatory validity): It is the ability of the scale to distinguish between the two ends of the characteristic that is measured in the order of the total scores that each individual in the sample gets on the scale, then we take a value of $27 \%$ (from both the upper and lower categories), then we apply the statistical method " $T$ " between the scores obtained. It is shown in Table No. (2), that the arithmetic mean for the upper group is (69.0), while the arithmetic mean for the lower group is (28.04), and the calculated " $\mathrm{T}$ " value is estimated at (31.8), which is a function at a significant level of (0.001). This indicates that there are statistically significant differences between the mean scores of the upper group and the lower group, which confirms the ability of the scale to distinguish between the two ends of the group in the characteristic. On this basis we consider the scale to have discriminatory validity and be acceptable.

Scale Reliability: the researcher employed a re-testing method on 10 adolescent students and the initial test was repeated after 15 days. The correlation coefficient was $0.95, \mathrm{P}=0.5$, thus indicating the strong correlation between the two applications and showing the scale's high consistency. By applying Alpha Cronbach formula (Table No.3), the consistency coefficient was 0.98 thus indicating the scale's high consistency.

Second tool: an electronic bullying scale, prepared by the researcher, neutralized the scale's items according to the previous studies, electronic bullying scales and study concepts. The scale's items total 23, with three estimated scores; "often" at 3 degrees, "sometimes" at 2 degrees and "never" at 1 degree, so the highest score of the scale is $23 \times 3=69$, the medium degree of the scale is $23 \times 2=46$ and the lower degree of the scale is $23 \times 1=23$.

Scale Validity: First; content validity: the researcher presented the scale to ten different professors in social work to assess the elements in terms of structure and relativity of the subject of the study. Accordingly, the researcher reconstructed and modified some phrases. Second; Table No. 1 shows that the correlation between items and the total score of the scale was of acceptable correlation and statistical significance. Third: the validity of the scale as a whole using the terminal comparison (Discriminatory validity): It is the ability of the scale to distinguish between the two ends of the characteristic that is measured in the order of the total scores that each individual in the sample gets on the scale, then we take a value of $27 \%$, from both the upper and lower categories, then 
we apply the statistical method "T" between the scores obtained. It is shown in Table No. (2) that the arithmetic mean for the upper group is (119.96), while the arithmetic mean for the lower group is (56.24), and the calculated " $\mathrm{T}$ " value is estimated at (24.67), which is a function at the significant level of (0.001). This indicates that there are statistically significant differences between the mean scores of the upper group and the lower group, which confirms the ability of the scale to distinguish between the two ends of the group in the characteristic, and on this basis we consider the scale to have discriminatory validity and be acceptable.

Scale Reliability: the researcher used the re-test method with ten adolescent students and the test was repeated 15 days later. The correlation coefficient was 0.97 at $\mathrm{p}=0.5$, thus indicating the strong correlation between the two applications, thus showing high scale consistency. By applying Alpha Cronbach formula (Table No.3), the consistency coefficient was 0.97 thus indicating the scale's high consistency.

Table (1): Validity Statistics for Bullying and Violence levels

\begin{tabular}{|l|c|c|}
\hline \multicolumn{1}{|c|}{ Variable } & $\mathrm{R}$ & $\mathrm{P}$ \\
\hline Bullying & 0.947 & $<0.001^{*}$ \\
\hline Psychological & 0.853 & $<0.001^{*}$ \\
\hline Verbal & 0.948 & $<0.001^{*}$ \\
\hline Physical & 0.856 & $<0.001^{*}$ \\
\hline Overall Violence & 0.983 & $<0.001^{*}$ \\
\hline
\end{tabular}

r: Pearson coefficient

*: Statistically significant at $\mathrm{p} \leq 0.05$

Table (2): Validity Statistics for Bullying and Violence levels

\begin{tabular}{|l|c|c|c|c|}
\hline \multicolumn{1}{|c|}{ Variable } & $1^{\text {st }}$ quartile & $3^{\text {rd }}$ quartile & $\mathrm{T}$ & $\mathrm{P}$ \\
\hline Bullying & $28.04 \pm 9.10$ & $69.0 \pm 0.0$ & $31.827^{*}$ & $<0.001^{*}$ \\
\hline Psychological & $20.90 \pm 7.13$ & $44.98 \pm 0.14$ & $23.888^{*}$ & $<0.001^{*}$ \\
\hline Verbal & $17.28 \pm 5.90$ & $35.94 \pm .42$ & $22.291^{*}$ & $<0.001^{*}$ \\
\hline Physical & $17.84 \pm 5.91$ & $38.94 \pm 0.43$ & $25.171^{*}$ & $<0.001^{*}$ \\
\hline Overall Violence & $56.24 \pm 18.26$ & $119.96 \pm 0.28$ & $24.674^{*}$ & $<0.001^{*}$ \\
\hline
\end{tabular}

t: Student t-tes $\quad *$ : Statistically significant at $\mathrm{p} \leq 0.05$

Table (3): Reliability Statistics for Bullying and Violence levels

\begin{tabular}{|l|c|c|}
\hline \multicolumn{1}{|c|}{ Variable } & No. of Items & Cronbach's Alpha \\
\hline Bullying & 23 & 0.974 \\
\hline Psychological & 15 & 0.971 \\
\hline Verbal & 12 & 0.984 \\
\hline Physical & 13 & 0.976 \\
\hline Overall Violence & 40 & 0.983 \\
\hline
\end{tabular}

The researcher applied a group of statistical laws and treatments among the SPSS package to process the research data in order to verify the study hypotheses and reach results. 


\section{Results:}

Table (4): Distribution of the studied cases according to bullying and violence levels $(n=213)$

\begin{tabular}{|c|c|c|c|c|c|c|c|c|}
\hline \multirow{2}{*}{ Variable } & \multicolumn{2}{|c|}{ Low } & \multicolumn{2}{|c|}{ Moderate } & \multicolumn{2}{|c|}{ High } & \multirow{2}{*}{$\begin{array}{l}\text { Total Score } \\
\text { Mean } \pm \text { SD }\end{array}$} & \multirow{2}{*}{$\%$ score } \\
\hline & No. & $\%$ & No. & $\%$ & No. & $\%$ & & \\
\hline Bullying $(23-69)$ & 40 & 18.8 & 72 & 33.8 & 101 & 47.4 & $52.74 \pm 17.30$ & 76.4 \\
\hline \multicolumn{9}{|l|}{ Violence Levels } \\
\hline Psychological $(15-45)$ & 30 & 14.1 & 39 & 18.3 & 144 & 67.6 & $37.95 \pm 10.92$ & 84.3 \\
\hline Verbal $(12-36)$ & 28 & 13.1 & 40 & 18.8 & 145 & 68.1 & $30.49 \pm 8.51$ & 84.7 \\
\hline Physical (13 - 39) & 31 & 14.6 & 63 & 29.6 & 119 & 55.9 & $31.26 \pm 9.36$ & 80.2 \\
\hline $\begin{array}{l}\text { Overall Violence } \\
(40-120)\end{array}$ & 31 & 14.6 & 63 & 29.6 & 119 & 55.9 & $99.70 \pm 27.37$ & 83.1 \\
\hline
\end{tabular}

Table No. 4 shows the study sample distribution according to domestic violence levels and electronic bullying. It was found that domestic violence was present among $83.1 \%$ of the sample, which is a high rate. The vast majority $(84.7 \%)$ was subject to verbal violence, followed by psychological violence $(84.3 \%)$ and finally physical violence $(80.2 \%)$. Electronic bullying was present in $76.4 \%$, thus indicating a high rate of electronic bullying among adolescents' who are subject to domestic violence.

Table (5): Correlation between Bullying and Violence $(n=213)$

\begin{tabular}{|l|c|c|}
\hline \multirow{2}{*}{ Violence } & \multicolumn{2}{|c|}{ Bullying } \\
\cline { 2 - 3 } & $\mathbf{R}$ & $\mathbf{P}$ \\
\hline Psychological & 0.750 & $<0.001^{*}$ \\
\hline Verbal & 0.649 & $<0.001^{*}$ \\
\hline Physical & 0.857 & $<0.001^{*}$ \\
\hline Overall Violence & 0.797 & $<0.001^{*}$ \\
\hline
\end{tabular}

r: Pearson coefficient

*: Statistically significant at $\mathrm{p} \leq 0.05$

Table No. 5 shows a statistically significant correlation, at $p$ $\leq$ 0.05(.001) between domestic violence, verbal, physical and psychological, and electronic bullying, as domestic violence increases, electronic bullying increases among adolescents.

Table (6): Multivariate linear regression for factor affecting bullying $(n=213)$

\begin{tabular}{|l|c|c|c|c|c|}
\hline \multicolumn{1}{|c|}{ Violence } & $\mathrm{B}$ & $\mathrm{T}$ & $\mathrm{p}$ value & $\mathrm{F}(\mathrm{p})$ & $\mathrm{R}^{2}$ \\
\hline Psychological (3) & -0.149 & 1.140 & 0.255 & \multirow{2}{*}{$224.015^{*}\left(<0.001^{*}\right)$} & \multirow{2}{*}{$76.3 \%$} \\
\cline { 1 - 4 } Verbal (2) & -0.429 & $3.312^{*}$ & $0.001^{*}$ & \\
\cline { 1 - 4 } Physical (1) & $2.078^{*}$ & $13.149^{*}$ & $<0.001^{*}$ & & \\
\hline
\end{tabular}

$\mathrm{F}, \mathrm{p}$ : $\mathrm{f}$ and $\mathrm{p}$ values for the model $\mathrm{R}^{2}$ : Coefficient of determination

B: Unstandardized Coefficients t: t-test of significance

*: Statistically significant at $\mathrm{p} \leq 0.05$ 
Table No. 6 shows the multiple regression analysis for the most influential aspect of domestic violence on electronic bullying. The $\mathrm{p}$ value of physical violence was highly significant at ?0.0001*, followed by the $p$ value of verbal violence which was highly significant at 0.001 and finally psychological violence that was insignificant; thus indicating that physical violence was the most influential factor on electronic bullying, followed by verbal violence then psychological violence. Physical violence affects electronic bullying by $76.3 \%$, which is a high percentage; thus, indicating that adolescents who are most subjected to physical domestic violence are those who are most likely to be involved in electronic bullying.

\section{Table (7): Difference between Bullying and Violence with socio} demographic data $(n=213)$

\begin{tabular}{|c|c|c|c|c|c|}
\hline & \multirow{2}{*}{ Bullying } & \multicolumn{4}{|c|}{ Violence } \\
\hline & & Psychological & Verbal & Physical & Overall \\
\hline \multicolumn{6}{|l|}{ Sex } \\
\hline Male & $55.26 \pm 15.76$ & $40.61 \pm 8.31$ & $34.44 \pm 4.88$ & $33.80 \pm 7.82$ & $108.85 \pm 19.65$ \\
\hline Female & $48.20 \pm 19.06$ & $33.17 \pm 13.24$ & $23.38 \pm 9.05$ & $26.67 \pm 10.18$ & $83.22 \pm 31.45$ \\
\hline$t(p)$ & $2.902\left(0.004^{*}\right)$ & $4.435\left(<0.001^{*}\right)$ & $9.885\left(<0.001^{*}\right)$ & $5.301\left(<0.001^{*}\right)$ & $6.438\left(<0.001^{*}\right)$ \\
\hline \multicolumn{6}{|l|}{ Parent education } \\
\hline Primary & $64.45 \pm 12.43$ & $42.72 \pm 7.79$ & $32.77 \pm 7.15$ & $36.63 \pm 6.48$ & $112.12 \pm 20.66$ \\
\hline Less than average & $47.48 \pm 14.98$ & $40.22 \pm 8.68$ & $32.58 \pm 6.07$ & $31.18 \pm 7.72$ & $103.99 \pm 19.80$ \\
\hline Secondary & $48.88 \pm 9.69$ & $31.46 \pm 6.59$ & $28.54 \pm 6.46$ & $26.19 \pm 6.66$ & $86.19 \pm 17.95$ \\
\hline University & $31.79 \pm 16.27$ & $20.63 \pm 10.66$ & $17.75 \pm 10.19$ & $17.75 \pm 8.95$ & $56.13 \pm 29.28$ \\
\hline $\mathbf{F}(\mathbf{p})$ & $\begin{array}{c}44.838 \\
\left(<0.001^{*}\right)\end{array}$ & $\begin{array}{c}50.872 \\
\left(<0.001^{*}\right)\end{array}$ & $\begin{array}{c}31.484 \\
\left(<0.001^{*}\right)\end{array}$ & $\begin{array}{c}47.462 \\
\left(<0.001^{*}\right)\end{array}$ & $\begin{array}{c}48.246 \\
\left(<0.001^{*}\right)\end{array}$ \\
\hline
\end{tabular}

\section{t: Student t-test}

F: F for ANOVA test

$\mathrm{p}$ : $\mathrm{p}$ value for association between different categories

*: Statistically significant at $\mathrm{p} \leq 0.05$

Table No. 7 shows the differences between the average degrees of domestic violence and the average degrees of electronic bullying according to the two variables, gender and parents' level of education. The study results indicated that there were highly statistically significant differences at $\mathrm{p} \leq 0.05(0.001)$ between the total average scores for male respondents (108.85) and the total average scores for female respondents (83.22) across the different violence aspects, favoring male respondents. There were highly significant differences $\mathrm{p} \leq 0.05(0.004)$ between average scores for electronic bullying among the two genders, favoring male respondents, thus indicating the higher number of instances of electronic bullying among male adolescents compared to female.

Significant differences were found between the average scores for the educational level of parents and the average scores for electronic bullying. The results showed high average scores of domestic violence (112.12) in families of parents with a primary and medium level of education, and high average scores for electronic 
bullying (64.45) by adolescents within those families; thus indicating the impact of parents' level of education on domestic violence (psychological, verbal and physical) and on the bullying behavior among their children. The lower the parents level of education, the higher the likelihood of domestic violence and the higher the level of electronic bullying among adolescents in those families.

\section{Discussion:}

The results showed that:

- The first main hypothesis of the study is valid; as there was a statistically significant positive correlation between the average scores of domestic violence (verbal, psychological and physical) affecting adolescents, and the average scores of electronic bullying among them. It was found that the adolescents within the sample were most likely to be subjected to verbal violence, followed by psychological violence and then physical violence. Thus, indicating the high level of verbal domestic violence affecting adolescents which is consistent with the results of AL-Masry (2004), Ghazwan (2015). and Abdel Gawad, (2020).

- The adolescents within the study sample showed a high percentage of involvement in electronic bullying, and many previous studies have shown that most bullies are adolescents, such as Al- Masry (2004), Ybarra \& Mitchell (2004), Ybarra, Espelage, Mitchell (2007), Hinduja \& Patchin (2008), Floros, Siomos, Fisoun, Dafouli, Geroukalis (2013), Almakanin, Younis, Alhiary (2018) and Bullying - National Crime Prevention, Council (2018).

- The results also indicated the positive correlation between electronic bullying and domestic violence, as electronic bullying among adolescents increases with the increase of domestic violence. The researcher believes that this result agrees with the study theories, for the social theory indicated that daily interactions taking place in an individual's life are a factor in facilitating or predicting violence. The results also agree with the suppressive theory, as the study results indicate that the form of violence most influencing electronic bullying behavior was physical violence, followed by verbal and psychological violence. Thus, confirming the theory stating that the more aggression the more suppression of such aggression, for the adolescent is likely to direct aggression towards another source, either directly or indirectly related to the main source, via electronic bullying behavior. Such results agree with the studies of Hamza (2001), Magzoub (2003), Sternberg, Baradaran, Abbot, Lamb, Guterman (2006), Mekky \& Ajam (2008), Ahmed (2008), Al-Sweety (2012), Abuleinin (2012), Tudkueaa, Laeheemb, Sittichaic (2019), Markwick, Bickerdike, Wilson-Evered, Zeleznikow (2019), Abdel Gawad (2020). 
- The results showed that the second main hypothesis; that there is no statistically significant differences between the average scores of domestic violence affecting adolescents and electronic bullying according to gender and parents' level of education, is invalid. The results indicated that there are differences between male and female respondent's average scores on the different aspects of violence favoring male respondents. Therefore; male adolescents are more often subjected to domestic violence than female adolescents, which agrees with the studies of Al- Masry (2004) and disagrees with the study of Al-Ratrout (2001).

- The results also showed that instances of electronic bullying among male adolescents are more frequent than those among females, which agrees with the studies of Al-Ammar (2016), but disagrees with the study of Hinduja \& Patchin (2008). The researcher attributed this to the nature of each of the sexes and the characteristics that prepare them for their interaction with their surrounding environment, which engenders the association of both domestic violence and cyber bullying with males rather than females.

- The results also showed that the parents' level of education affected both domestic violence and electronic bullying behavior among children. It was found that the lower the parents' level of education was, the higher the level of domestic violence and the higher the level of electronic bullying. The researcher explains the necessity to educate parents about using correct parenting methods to eliminate domestic violence and provide positive interaction and understanding with their children; thus eliminating electronic bullying behavior among them. This agrees with the results of Katibi (2012), Al-Qous (2014), Ghazwan (2015) and Tudkueaa, Laeheemb, Sittichaic (2019).

\section{Recommendations:}

- Performing more scientific research in the field of domestic violence and electronic bullying to provide accurate data for those who work in this field.

- Working on enhancing the dialogue within the family through educational programs targeting families and focusing on the importance of effective social upbringing.

- Inviting governmental and non-governmental institutions to enhance social culture combating domestic violence and focusing on the media's role in raising awareness of appropriate methods for raising children.

- Passing laws and regulations involving domestic violence in order to avoid its negative impacts. 
- Providing care for domestic violence victims through the governmental and non-governmental institutions of social care thus avoiding a deterioration in their behavior in the future.

- Create family guidance centers in governments and major cities and provide them with professional qualified staff.

- Families' participation in school meetings and decisions to prevent the occurrence of electronic bullying and increase control over social media sites.

- Adopting educational programs to inform students about the hazards of technology, and demonstrate using it positively to avoid problems resulting from electronic bullying among school students.

- Students' participation in cultural, social and sports activities to give them the chance for positive social communication.

\section{Limitation:}

The researcher had some difficulty executing the research in terms of collecting data about electronic bullying, and a lack of honesty in some responses to the research tools which had to be eliminated from the results. The researcher overcame such difficulties with the help of social workers and by confirming the confidentiality of the data collected.

\section{Suggested future research:}

An educational family program to improve the parenting methods among families of adolescents who are subjected to domestic violence, thus developing communication skills and eliminating the negative impact of electronic bullying. An educational family program to reduce electronic bullying among adolescents and college students.

\section{References:}

Abdel Gawad, A. M. (2020) The relationship between family violence directed towards children and their practice of school violence in a context Behavioral individual service, Journal of Studies in Social Work and Humanities Issue 49, Volume 3, January, p.716 https://jsswh.journals.ekb.e

Abu Zeid, O. O. (2010). Media and Domestic violence. Riyadh, KSA: Naif Arab University for security sciences, p.138.

AbulEinin, A. M. (2012). The impact of domestic violence on criminality. Faculty of Sharia and Law, 14, 119- 200. Retrieved from https://jfslt.journals.ekb.eg/article_14170_a9bb67716adc8814b744 ed9218c4024d.pdf

Ahmed, R. Y. (2008). The Characteristic of rural family and their relation to parents' violence. (Unpublished master thesis), Damascus University.

AL-Ammar, A. Y. (2016). Electronic bullying and its relation to internet addiction under some demographic variables. Educational scientific research journal, 17, 224. Retrieved from https://ejsw.journals.ekb.eg/journal/authors.note 
Al-Faraia, O. (2006). Domestic violence against children and its relation to psychological security. (Unpublished Mater thesis), Jordan: Mouta University.

Al-Marawaty, N. M. (2010). Domestic violence. Arab Journal for security studies and training, 51(26), 83-142. Retrieved from http://repository.nauss.edu.sa/handle/123456789/54624

Al-Masry, A. (2004). Parents' verbal abuse against children in Karak governorate and their relation to some demographic variables, a survey study. (Unpublished master thesis), Mouta, Jordan: Mouta University.

Al-Qous, M. F. (2014). Social factors related to domestic violence against children. (Mater thesis), Naif Arab University for security sciences, Faculty of Social and Administrative sciences, Sociology Department, social well- being and rehabilitation division. p.118125

Al-Ratrout, S. A. (2001). Types of abuse against children by family members and their relation to some social and economic changes. (Unpublished master thesis), Amman, Jordan: Jordanian University.

Al-Sweety, A. (2012). Domestic violence against children and its relation to their security among a sample of 9 graders in Al- Khalil city. Azhar University journal in Ghaza, Human Science series, 1(14), 281- 310. Retrieved from http://www.alazhar.edu.ps/journal123/human_Sciences.asp?typeno=0

Almakanin, H.A., Younis, N.A., \& Alhiary. G.M. (2018). Electronic bullying among a sample of behaviorally and emotionally disturbed students in Azzarqa city, Al-hashemia University, Jordan. Psychological and Educational studies Journal, Sultan Qabous University, Journal, 12, 1:179-197. doi: http://dx.doi.org/10.24200/jeps.vol12iss1

Arslan, S., et al (2012). Cyberbullying Among Primary School Students in Turkey: Self-Reported Prevalence and Associations with Home and School Life. Cyberpsychology, behavior and social networking, 15(10), 527-533.doi: 10.1089/cyber.2012.0207

Bardi M. \& Tarli, B. (2001). A survey on parent-child conflict resolution: intra family violence in Italy. Child abuse and neglect, 6,839-853. doi: 10.1016/s0145-2134(01)00242-3

Bennett, L. (2015). The role of social workers in responding effectively to domestic abuse. Retrieved from: http://www.safelives.org.uk/practice blog/role-social-workersresponding-effectively-domestic-abuse

Bou-tabbal, S.\& Maousha, A. (2013). Domestic violence against the child, University of Qasedi Mesbah, Faculty of Human and Social Sciences, Social Sciences Department, National Second Forum of communication and family well- being.

Bullying - National Crime Prevention Council". Available from: https://www.ncpc.org/resources/cyberbullying/. [Accessed in: Dec, 2012] 
Desouky, M. M. (2002). The use of reality therapy in case work to treat some behavioral disorders among abused children. Social work and Human sciences Journal, Social Work Faculty, Helwan University, $21,129$.

Fayed, H. A. (2001). Aggression and depression in modern time, a comprehensive view. Alexandria: Scientific Bureau for computer and publication, p.35.

Floros, G.D., et al (2013). Adolescent Online Cyberbullying in Greece: The impact of parental online security practices, bonding, and online impulsiveness. Journal of School Health, 83(6), 445-453.

Ghazwan, A. A. (2015). Domestic violence against children and its reflection on personality, social field study in Hella City. Journal of University of Babylon, 23(4), 2155-2175. Retrieved from https://www.iasj.net/iasj?func=article\&aId=107785

Hamza, J. (2001). Parents' abusive behavior against the children and its impact upon their psychological security. Journal of Psychology, 15,58 .

Hinduja, S., \& Patchin, J.W. (2008). Cyberbullying: an exploratory analysis of factors related to offending and victimization. Deviant Behavior, 29, 129-156. doi.org/10.1080/01639620701457816

Juvonen, J., \& Gross, E. (2008). Extending the school grounds? Bullying experiences in cyberspace. The Journal of School Health, 78(9), 496505. doi:10.1111/j.1746- 1561.2008.00335.x

Katibi, M. E. (2012). Domestic violence against children and its relation to psychological loneliness. Damascus University Journal, 28(1), 67-106. Retrieved from http://www.damascusuniversity.edu.sy/ mag/edu/images/stories/67-106--.pdf

Kowalski, R.M., Limber, S.B, \& Agatston, P.W. (2012). Cyberbullying: Bullying in the Digital Age, $\left(2^{\text {nd }}\right.$ ed). USA: Second Edition by Blackwell Publishing Ltd.

Lenhart, A., et al (2007). Teens and social media: The use of social media gains a greater foothold in teen life as they embrace the conversational nature of interactive online media. Washington, D.C.: Pew Internet \& American Life Project.

Magzoub, A. (2003). Violence in Egyptian families. Cairo: National Social and Criminal research Center, p.106.

Markwick, K., et al (2019). Technology and Family Violence in the Context of Post-Separated Parenting. Australian and New Zealand Journal of Family Therapy, 40, 143-162, doi: 10.1002/anzf.1350.

Megan A. (2014) Cyberbullying. JAMA Pediatrics, 168(5), 500. doi:10.1001/jamapediatrics.2013.3343

Mekky, R. A. (2008). The paradigm of violence, justified violence and convicted violence. Lebanon, Beirut: University Institution for studies and publication. p.106.

Phillips, J \& Vandenbroek, P (2014). Domestic, family and sexual violence in Australia: an overview of the issues. Department of Parliamentary Services, Canberra. 14 October 
Šléglová, V., \& Cerna, A. (2011). Cyberbullying in Adolescent Victims: Perception and Coping. Journal of Psychosocial Research on Cyberspace, 5(2), 4. Retrieved from https://cyberpsychology.eu/ article/view/4248/3294

Sternberg, K.D., et al. (2006). Type of violence, Age and Gender Different in the effect of Family violence on children Behaviour problems: Amega-Analysis. Developmental Review,26(1), 89-112.doi: 10.1016/j.dr.2005.12.001

Tokunaga, R. S. (2010). Following you home from school: A critical review and synthesis of research on cyberbullying victimization. Computers in Human Behavior, 26, 277-287.doi: 10.1016/j.chb.2009.11.014

Tudkueaa, T., Laeheemb, K., Sittichaic, R. (2019). Development of a causal relationship model for cyber bullying behaviors among public secondary school students in the three southern border provinces of Thailand. Children and Youth Services Review,102:145-149. doi.org/10.1016/j.childyouth.2019.05.013

UNICEF (2015). Violence against children in Egypt, a qualitative survey and study in Cairo, Alexandria and Asyut. Cairo: National Council of Childhood and Motherhood and UNICEF Egypt.

Webb, R. (2013). The Adverse Childhood Experiences (ACE) Study Implications for Mother's \& Children's Exposure to Domestic Violence. Washington, DC: National Association of Social Workers.

White J (2019). Addressing school violence and bullying: Evidence review. Edinburgh: NHS Health Scotland. p.5

Willard, N. E. (2007). Cyber bullying and cyber threats. Champaign, IL: Research Press.

Wilson, M.H., \& Webb, R. (2018). Social Justice Brief, Social Work's Role in Responding to Intimate Partner Violence. Washington, DC: National Association of Social Workers.

World Health Organization (WHO). (2015), Who Preventing youth violence: An overview of the evidence. Geneva: WHO.

Ybarra, M. L., \& Mitchell, K. J. (2004). Online aggressor/targets, aggressors, and targets: A comparison of associated youth characteristics. Journal of Child Psychology and Psychiatry, 45, 1308-1316. DOI: 10.1111/j.1469-7610.2004.00328.x

Ybarra, M. L., Espelage, D. L., Mitchell, K. G. (2007). The Co-occurrence of Internet Harassment and Unwanted Sexual Solicitation Victimization and Perpetration: Associations with Psychosocial Indicators. Journal of Adolescent Health, 41, S31-S41.Doi: 10.1016/j.jadohealth.2007.09.010

Zhou, Z, et al., (2013). Cyberbullying and its risk factors among Chinese high school students. School Psychology International, 34(6) 630-647. https://doi.org/10.1177/0143034313479692 